\title{
MECHANICAL BEHAVIOR OF FETAL DURA MATER UNDER LARGE DEFORMATION BIAXIAL TENSION
}

\author{
Donita I. Bylski*, Timothy J. Kriewall †, Nuri AkKas $\ddagger$ and John W. Melvin \\ - Biomechanics, Trauma and Sports Medicine Laboratory, The University of Michigan, Ann Arbor. \\ MI 48109, U. A ; +Otologic Products Division. 3M Company 270-2A-10 3M Center, St. Paul. \\ MN 55144, U.S.A ; † Department of Civil Engineering. Middle East Technical University. Ankara. \\ Turkey; $\S$ Department of Mechanical Engineering and Applied Mechanics. The University of Michigan. \\ Ann Arbor, MI 48109. U.S.A
}

\begin{abstract}
The mechanical behatior of fetal dura mater was investigated by means of a biaxial tension test designed to simulate the constraints imposed on the membrane by the cranial bones. The experimental results are compared with the theoretical results obtained by using two published strain energy functions: one defined by Mooney and Rivlin (MR) and the other by Skalak, Tozeren, Zarda and Chien (STZC). The latter constitutive relations fit the experimental results consistently well. The STZC stiffness values from this series of tests are compared with those from membrane inflation tests performed previously and reported elsewhere by the authors.
\end{abstract}

\section{NOMENCLATURE}

$\begin{array}{ll}Q & \text { point on membrane in initial state } \\ Q^{\prime} & \text { point on membrane in deformed state } \\ r & \text { radial component of } Q \\ Z & \text { axial component of } Q \\ \rho & \text { radial component of } Q^{\prime} \\ \xi & \text { axial component of } Q^{\prime} \\ a & \text { initial height } \\ b_{0} & \text { outer radius of test specimen } \\ b_{1} & \text { inner radius of test specimen } \\ \dot{\lambda}_{1} & \text { meridional stietch ratio } \\ \lambda_{2} & \text { circumferential stretch ratio } \\ \lambda_{3} & \text { normal stretch ratio } \\ d s & \text { meridional arc length in initial configuration } \\ d S & \text { meridional arc length in deformed configuration } \\ T_{1} & \text { membrane force in meridional direction } \\ T_{2} & \text { membrane force in circumferential direction } \\ K_{1} & \text { principal curvature in meridional direction } \\ K_{2} & \text { principal curvature in circumferential direction } \\ (\quad)^{\prime} & \text { differentiation with respect to } r \\ \eta & \rho^{\prime} \\ \Omega & =\left[1+\left(z^{\prime}\right)^{2}\right]^{0.3} \\ \lambda_{1} & =\Omega_{1} \lambda_{1} \\ h & \text { initial nominal membrane thickness } \\ C_{1}, C_{2} & \text { material constants in MR model with dimensions } \\ \alpha & \text { of stress } \\ B, C & =C_{2} / C_{1} \\ & \text { material constants in STZC model with dimen- } \\ \Gamma & \text { sions of force per unit length } \\ & =B / C\end{array}$

\section{INTRODUCTION}

Although relatively few infants in the United States die during birth (1-3 per 1000 live births), the cause of about half of the deaths remains unknown (Lillien, 1970). The causes of mental retardation are also largely unexplained. Quilligan and Paul (1975) postulate that a better understanding of labor and delivery would reduce by $50 \%$ the incidence of mental and

Receired 17 July 1984; in revised form 20 June 1985. physical handicaps incurred by the fetus intrapartum.

During birth, the shape of the fetal head changes due to mechanical loading by the maternal birth canal in a process called fetal skull molding. Excessive molding has been implicated in conditions ranging in severity from subtle psychoneurological disorders to mental retardation, cerebral palsy and even death (Holland, 1922; Churchill, 1970; Glenting, 1970; Willerman, 1970 a, b; Fianu, 1976; Wigglesworth and Husemeyer, 1977; Stewart and Philpott, 1980). Yet, intrapartum diagnosis of excessive molding is beyond the capabilities of present day obstetrics (Kriewall and McPherson, 1981).

Despite the undisputed importance of head molding in both normal and abnormal labor, few researchers have attempted to quantify the magnitudes and directions of loads typically exerted on the fetus during delivery, or to define the response of the fetus to these loads. The problem may be divided into three distinct areas: (1) defining the geometry of the fetal head during and after birth, (2) measuring the material properties of the components of the fetal head, and (3) measuring the loads applied to the fetal head during labor. Information from each of these three areas may then be used to assemble a mathematical model of the fetal skull, similar to those developed for the adult skull. Such a model may, in time, assist a clinician who needs to manage difficult labors without introducing potentially harmful procedures.

Preliminary data are available from previous investigations on the pressure distributions on the fetal head during normal labor (Lindgren, 1960; Schwarcz et al., 1970; Hashimoto et al., 1980); the geometry of the fetal skull intrapartum (Borell and Fernstrom, 1958) and post-partum (Kriewall et al., 1977); and the mechanical properties of fetal cranial bone (McPherson and Kriewall, 1980 a; Kriewall et al., 1981; Kriewall, 1982). These data have been used to construct a finite element model of the fetal parietal bones (McPherson and 
Kriewall, 1980b). Results from that model indicate that the thinner, more flexible preterm parietal bone is capable of undergoing larger deformations than term parietal bone under the same applied pressures. This may be a contributing factor to the increased incidence of birth trauma experienced by the preterm fetus.

However, unlike the rigid adult skull, the fetal skull is composed of flexible plates with an underlying soft tissue membrane, called the dura mater, that adheres closely to the inner surface of the bones and forms the connections, or sutures, between the plates. Thus, dura mater is an essential structural component of the fetal skull. Because the initial model did not include the restraining effect of the soft tissues, results from the model indicated that the posterior portion of a parietal bone could cross the sagittal plane and hence 'overlap' the opposite parietal bone. Such a condition is not observed clinically. The next phase of model development, then, must include the restraint effects of the dura mater.

Fetal dura mater has previously been tested and analyzed in biaxial tension induced by inflation (Kriewall et al., 1983). The inflation test is a basic materials testing technique developed for membranous materials (Wineman, 1976). Such a basic materials test is the best approach to study the interdependence between the stiffness of a material and physiological variables such as gestational age, since the material characterization parameters are not dependent on test geometry. In fact, results from the inflation study showed that the stiffness of the dura was significantly correlated to birthweight $(p<0.05)$, although the sample size was admittedly limited. However, it is unclear how the stiffness values derived from the inflation test relate to the physiologic state, as the boundary conditions are much different. The purpose of this study is to characterize fetal dura mater in a biaxial tension test specifically designed to simulate the constraints imposed on the dura mater by the cranial bones.

Previous studies on adult dura mater have indicated that it, like other soft tissues, is anisotropic and viscoelastic, but that the general variability in the tissue tends to overshadow those effects (Melvin et al., 1970). Fetal dura is assumed to behave similarly. Therefore, anisotropy and viscoelasticity will be ignored in this initial model. In addition, the birth process is relatively slow, and fetal skull molding is a large deformation process. Borell and Fernstrom (1958) found that the biparietal diameter may increase as much as $10 \mathrm{~mm}$, a change of about $10 \%$. This is consistent with the findings of Kriewall et al. (1977). For these reasons, our model assumes that dura mater is an isotropic, nonlinearly elastic, incompressible, and homogeneous material undergoing large static deformation. The theory of nonlinear elastic membranes undergoing large deformation is described by various authors (e.g. Green and Adkins, 1970; Feng and Yang, 1973; Yang and Feng, 1970; Benedict et al., 1979; Bogen and McMahon, 1979).

\section{MATERIALS AND METHODS}

Dura mater was excised from calvaria of fetuses that died from causes that would not be expected to affect the development of the dura. The estimated gestational ages ranged from 30 to 42 weeks; fetal weights ranged from 987 to 3612 grams-force $\left(g_{f}\right)$. The mean of the nominal thicknesses was $0.57 \mathrm{~mm}$. Table 1 presents data regarding the fetuses and their dura mater.

After excision, the dura was immediately stored in Ringer's solution. Some specimens were acquired prior to test development and were frozen. The others were refrigerated at $5^{\circ} \mathrm{C}$ until testing began. Although the small sample size precluded the study of storage effects on the stiffness of the dura, the two fresh specimens will be seen to exhibit loading curves within the range of the frozen specimens.

Just prior to testing, the dura was allowed to warm to room temperature. Its thickness was measured with a dial indicator in at least four randomly selected locations. The measurements were taken upon initial contact with the membrane, before obvious tissue compression occurred. The dura was kept wet at all times. Circular specimens $40 \mathrm{~mm}$ in diameter were cut from sections of membrane taken from the parietal or frontal cranial bones.

The clamping assembly, shown in Fig. 1, consisted of an inner disk and outer concentric ring. The contacting sides of both clamps had hard knurled rubber surfaces to minimize slippage. A centering mount below the lower disk and a companion piece used to center the upper disk (not shown in the figure) ensured easy alignment of the apparatus. The dura mater was placed between the clamps. Four holes were punched through the dura for the screws that joined the inner clamps.

The resulting free ring of dura had an inner diameter of $15 \mathrm{~mm}$ and an outer diameter of $25 \mathrm{~mm}$, hence an average circumference of $63 \mathrm{~mm}$. This circumference is on the order of suture lengths and the width of free dura is approximately the suture width of a full-term fetus. The average nominal thickness of the samples was $0.57 \mathrm{~mm}$. The width to thickness ratio of the free dura was about $10: 1$, so tensile forces predominated, as in vivo.

The outer ring was mounted to the crosshead of an Instron tensile test machine. The inner disk was connected to a load cell; a linear variable differential transformer (LVDT) measured displacement. An $x-y$ rocorder plotted toad vs deflection. The load was applied along the vertical centerline of the system. To ensure only vertical load transmission, a universal joint coupled the fixture and the load cell. Each specimen was preconditioned by cycling at least six times to increasingly higher loads at a rate of $0.02 \mathrm{~mm} \mathrm{~s}^{-1}$, then loaded to failure.

Two biaxial tension tests were performed on $0.5 \mathrm{~mm}$ thick sheets of styrene butadiene rubber from the same stock of material to check the reproducibility of the experimental procedure. Rubber may be regarded as 
Table 1. Biographical data for test material

\begin{tabular}{|c|c|c|c|c|c|c|c|}
\hline \multicolumn{2}{|c|}{ Calvarium No. } & \multirow{2}{*}{$\begin{array}{c}\begin{array}{c}\text { Estimated } \\
\text { gestational } \\
\text { age (weeks) }\end{array} \\
42\end{array}$} & \multirow{2}{*}{$\frac{\operatorname{Sex}}{\mathrm{F}}$} & \multirow{2}{*}{$\begin{array}{l}\begin{array}{c}\text { Weight } \\
\left(g_{f}\right)\end{array} \\
2850\end{array}$} & \multirow{2}{*}{$\begin{array}{c}\begin{array}{c}\text { Nominal } \\
\text { thickness }(\mathrm{mm})\end{array} \\
0.66\end{array}$} & \multirow{2}{*}{$\begin{array}{l}\text { Storage } \\
\text { temperature } \\
1 \mathrm{Cl}\end{array}$} & \multirow{2}{*}{$\begin{array}{l}\text { Cause of death } \\
\text { Hypoplastic } \\
\text { left heart }\end{array}$} \\
\hline 15 & $\begin{array}{l}\text { Parietal } \\
\text { left }\end{array}$ & & & & & & \\
\hline \multirow[t]{4}{*}{16} & $\begin{array}{l}\text { Parietal } \\
\text { left a }\end{array}$ & 39 & $\mathrm{~F}$ & 2922 & 0.60 & -10 & Aortic atresia \\
\hline & $\begin{array}{l}\text { Parietal } \\
\text { left } b\end{array}$ & & & & 0.61 & -10 & \\
\hline & $\begin{array}{l}\text { Frontal } \\
\text { left }\end{array}$ & & & & 0.61 & -10 & \\
\hline & $\begin{array}{l}\text { Frontal } \\
\text { right }\end{array}$ & & & & 0.61 & -10 & \\
\hline 17 & $\begin{array}{l}\text { Parietal } \\
\text { left }\end{array}$ & 30 & $\mathbf{M}$ & 987 & 0.62 & -10 & $\begin{array}{l}\text { Cystadenomatoid } \\
\text { malformation lung }\end{array}$ \\
\hline \multirow[t]{2}{*}{18} & $\begin{array}{l}\text { Parietal } \\
\text { left a }\end{array}$ & 40 & $\mathbf{M}$ & 3612 & 0.55 & -10 & $\begin{array}{l}\text { Diaphragmatic } \\
\text { hernia }\end{array}$ \\
\hline & $\begin{array}{l}\text { Parietal } \\
\text { left } b\end{array}$ & & & & 0.53 & -10 & \\
\hline 19 & $\begin{array}{l}\text { Parietal } \\
\text { right }\end{array}$ & 40 & $M$ & 2550 & 0.40 & -10 & $\begin{array}{l}\text { Irisomy } 21 \\
(G-G)\end{array}$ \\
\hline 20 & $\begin{array}{l}\text { Parictal } \\
\text { right }\end{array}$ & 33 & $\mathbf{M}$ & 1783 & 0.57 & 5 & $\begin{array}{l}\text { Respiratory } \\
\text { distress syndrome }\end{array}$ \\
\hline 21 & $\begin{array}{l}\text { Parietal } \\
\text { right }\end{array}$ & 30 & $\mathrm{~F}$ & 1400 & 0.53 & 5 & $\begin{array}{l}\text { Respiratory } \\
\text { distress syndrome }\end{array}$ \\
\hline
\end{tabular}
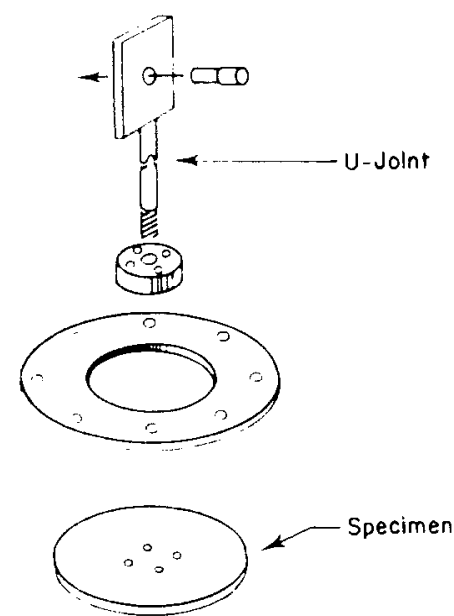

8
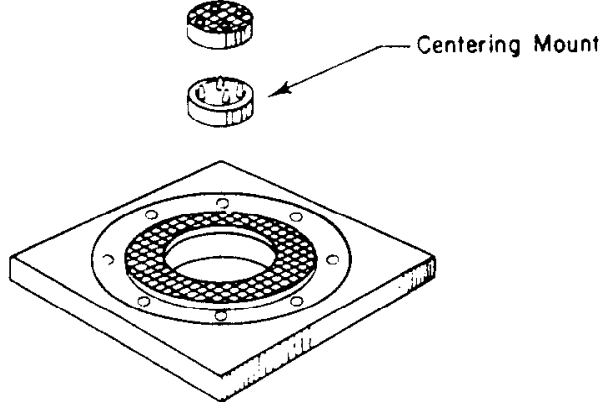

Fig. 1. The membrane is clamped into the fixture shown for the biaxial tension test. an isotropic and incompressible material with a strain energy function of the Mooney-Rivlin type (Green and Adkins, 1970). It has been studied experimentally and theoretically elsewhere (Wineman, 1976).

\section{ANALYSIS}

The geometry of the membrane in its initial and deformed configurations is shown in Figs 2 and 3 . The loading and geometry are axisymmetric. The point $Q$ defined by the coordinates $(r, z)$ in the initial configuration is displaced to point $Q^{\prime}$ defined by $(\rho, \zeta)$ in the deformed configuration. The initial state of the dura mater was represented as a truncated cone because it was not possible to place the dura flat in the test fixture relative to the measuring capability of the LVDT, and because the stiffness of soft biological tissues at small strains is very small (Decraemer et al., 1980). The equation of this reference configuration is

$$
z=a\left(b_{o}-r\right) /\left(b_{o}-b_{i}\right)
$$

where $b_{i}$ and $b_{o}$ are the inner and outer radii, respectively, of the truncated cone and $a$ is the initial height. The problem is to determine the deformed configuration when the initial configuration and load are given.

The equilibrium and compatibility equations are obtained in a manner similar to that presented elsewhere for a spherical cap inflation problem (Wineman et al., 1979; Pujara and Lardner, 1978; Kriewall et al., 

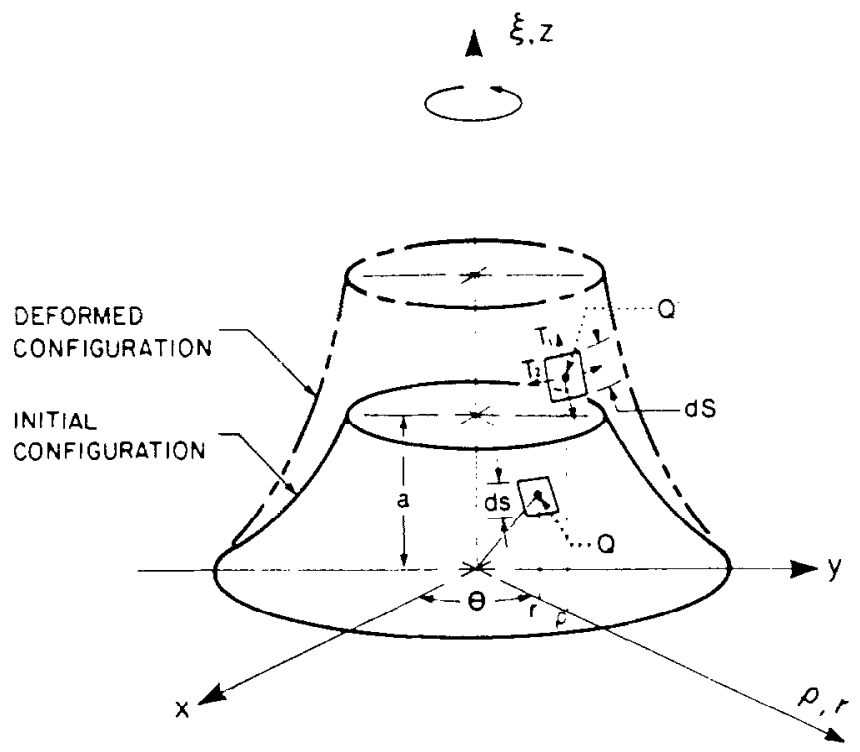

Fig. 2. Geometry of the biaxial tension test is shown.

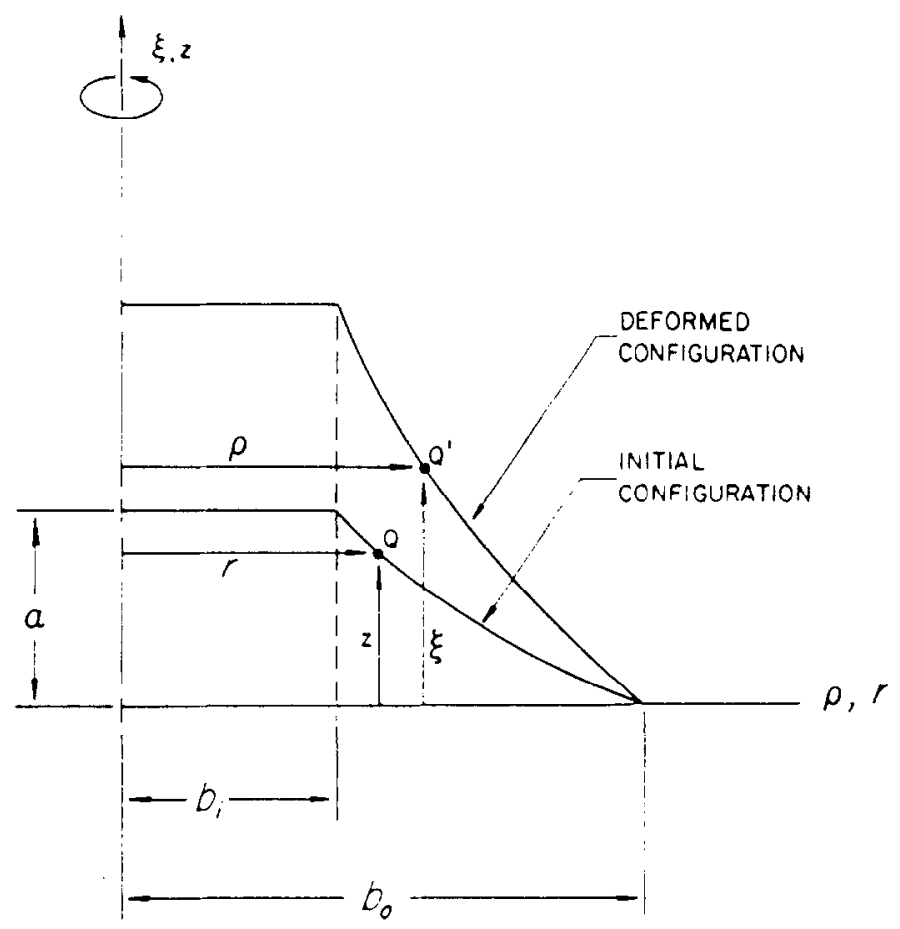

Fig. 3. Stretch ratios are defined by comparing the axisymmetric membrane in its initial and deformed configurations.

1983). The only differences arise from the negative curvature of the deformed membrane profile and the absence of internal pressure. However, the development will be repeated here for the sake of completeness.

\section{Governing equations}

The principal directions of the stresses and stretch ratios at each point on the membrane are in the meridional, circumferential, and normal directions. The stretch ratios in these directions are $\lambda_{2}, \lambda_{2}$ and $\lambda_{3}$, respectively. By definition,

$$
\begin{gathered}
\lambda_{1}=\mathrm{d} S / \mathrm{d} s \\
\lambda_{2}=\rho / r
\end{gathered}
$$

where $\mathrm{d} S$ and $\mathrm{d} s$ are the meridional arc lengths in the 
deformed and undeformed configurations. From incompressibility

$$
\lambda_{1} \lambda_{2} \lambda_{3}=1
$$

For an element cut from the membrane of revolution of Fig. 3 in the deformed configuration, the force balance equations in the principal directions are

$$
\begin{gathered}
\mathrm{d} T_{1} / \mathrm{d} \rho+\left(T_{1}-T_{2}\right) / \rho=0 \\
K_{1} T_{1}+K_{2} T_{2}=0
\end{gathered}
$$

where $T_{1}$ and $T_{2}$ are the membrane forces in the principal directions and $K_{1}$ and $K_{2}$ are the principal curvatures.

By writing the principal curvatures in terms of the principal stretch ratios $\lambda_{1}$ and $\lambda_{2}$, substituting them into equations (3), and transforming the resulting equations to the initial configuration, the equilibrium equations result

$$
\begin{gathered}
T_{1}^{\prime}=-\eta\left(T_{1}-T_{2}\right) / r \lambda_{2} \\
T_{1}\left(\bar{\lambda}_{1}^{\prime} \eta-\bar{\lambda}_{1} \eta^{\prime}\right) /\left[\lambda_{1}^{2}\left(\bar{\lambda}_{1}^{2}-\eta^{2}\right)^{0.5}\right] \\
-\left[T_{2}\left(\bar{\lambda}_{1}^{2}-\eta^{2}\right)^{0.5}\right] / r \lambda_{1} \lambda_{2}=0
\end{gathered}
$$

in which

$$
\begin{aligned}
()^{\prime} & \equiv \mathrm{d}() / \mathrm{d} r \\
\eta & =\rho^{\prime} \\
\bar{\lambda}_{1} & =\lambda_{1} \Omega \\
\Omega & \equiv\left[1+\left(z^{\prime}\right)^{2}\right]^{0.5} .
\end{aligned}
$$

The compatibility condition is

$$
\lambda_{2}^{\prime}=\left(\eta-\lambda_{2}\right) / r \text {. }
$$

In their most general forms, the constitutive equations express $T_{1}$ and $T_{2}$ in terms of $\lambda_{1}$ and $\lambda_{2}$ as follows

$$
T_{1}=F\left(\lambda_{1}, \lambda_{2}\right), \quad T_{2}=G\left(\lambda_{1}, \lambda_{2}\right)
$$

where $F$ and $G$ are general functions. Substituting equations (7) into cquations (4) we obtain

$\lambda_{i}=$

$$
\Omega / \frac{\partial F}{\partial \lambda_{1}}\left[\frac{-\bar{\lambda}_{1}(F-G)}{r \lambda_{2} \Lambda}-\frac{\partial F}{\partial \lambda_{2}}\left(\frac{\bar{\lambda}_{1}}{r \Lambda}-\frac{\lambda_{2}}{r}\right)+\frac{\partial F}{\partial \lambda_{1}} \frac{\lambda_{1} \Omega^{\prime}}{\Omega^{2}}\right]
$$

$$
\Lambda^{\prime}=G \bar{\lambda}_{1}\left(\Lambda^{2}-1\right) / r F \lambda_{2}
$$

where $\Lambda=\bar{\lambda}_{1} / \eta$. The compatibility condition, equation (6), can be written as

$$
\lambda_{2}^{\prime}=\left(\lambda_{1} / r \Lambda\right)-\left(\lambda_{2} / r\right) .
$$

Equations (8), (9) and (10) suffice to determine the three unknowns $\bar{\lambda}_{1}, \lambda_{2}$ and $\Lambda$.

The boundary conditions for $r=b_{i}$ are

$$
\lambda_{1}=\lambda_{i}, \quad \lambda_{2}=1, \quad \Lambda=\Lambda_{i}
$$

in which $\lambda_{i}$ is assumed to be given in the numerical procedure and $\Lambda_{i}$ is allowed to vary in the numerical solution. The boundary condition at $r=b_{0}$ is $\lambda_{2}=1$.
Once the membrane forces in the conical membrane are determined, the external force applied on the inner disk can be calculated from equilibrium considerations.

\section{Constitutive relations}

In studies of elasticity of bodies undergoing finite deformation, a commonly used approach is to postulate the form of an elastic potential, or strain energy function (Green and Adkins, 1970). A discussion of various functions can be found in Crisp (1972) and Fung (1981). The constitutive equations selected for the present study are the material models of Mooney and Rivlin (MR) (Green and Adkins, 1970) and of Skalak et al. (STZC) (1973).

The MR constitutive relations are

$$
\begin{aligned}
& T_{1}=\left[2 h C_{1}\left(\lambda_{1}^{2}-\lambda_{1}^{-2} \lambda_{2}^{-2}\right)\left(1+\alpha \lambda_{2}^{2}\right)\right] / \lambda_{1} \lambda_{2} \\
& T_{2}=\left[2 h C_{1}\left(\lambda_{2}^{2}-\lambda_{1}^{-2} \lambda_{2}^{-2}\right)\left(1+\alpha \lambda_{1}^{2}\right)\right] / \lambda_{1} \lambda_{2}
\end{aligned}
$$

where $h$ is the initial, uniform thickness of the membrane, $\alpha=C_{2} / C_{1}$, and $C_{1}$ and $C_{2}$ are the material constants with dimensions of stress.

The STZC constitutive relations are

$$
\begin{aligned}
& T_{1}=\left(C \lambda_{1} / 2 \lambda_{2}\right)\left[\Gamma\left(\lambda_{1}^{2}-1\right)+\lambda_{2}^{2}\left(\lambda_{1}^{2} \lambda_{2}^{2}-1\right)\right] \\
& T_{2}=\left(C \lambda_{2} / 2 \lambda_{1}\right)\left[\Gamma\left(\lambda_{2}^{2}-1\right)+\lambda_{1}^{2}\left(\lambda_{1}^{2} \lambda_{2}^{2}-1\right)\right]
\end{aligned}
$$

where $\Gamma=B / C$, and $B$ and $C$ are the material constants with dimensions of force per unit length. Equations (8), (9) and (10) were solved with the Runge-Kutta method. The numerical integration was started at $r=b_{i}$ and the generator of the membrane was divided into a mesh of twenty equal divisions. The solution was completed when the radius of the deformed membrane at the last mesh point was equal to the initial outer radius within a specified error tolerance.

\section{RESULTS}

Figure 4 compares the experimental and analytic results. Plotted in Fig. 4 a are both SBR experimental loading curves, and poit.ts derived from the MR and STZC models. The similarity of the experimental curves demonstrates that the test protocol produced repeatable results. The two analytic curves clearly show that the MR model is able to describe the shape of the SBR curve, whereas the STZC model predicts a material that is too soft at low loads and too stiff at the higher levels. These features, however, are required to describe the response of the dura mater, as shown in Fig. 4b. Here, the STZC results are clearly superior. This was consistently true for all the dura tests.

Figure 5 presents all eleven dura loading curves with the STZC stiffnesses $(C)$ that best fit. The mean and sample standard deviation of the $C$ s from all tests, in $\mathrm{g}_{\mathrm{f}} \mathrm{cm}^{-1}$, are 2000 and 840 , respectively.

Statistics were computed for the STZC stiffnesses. No correlation was found between fetal birthweight 

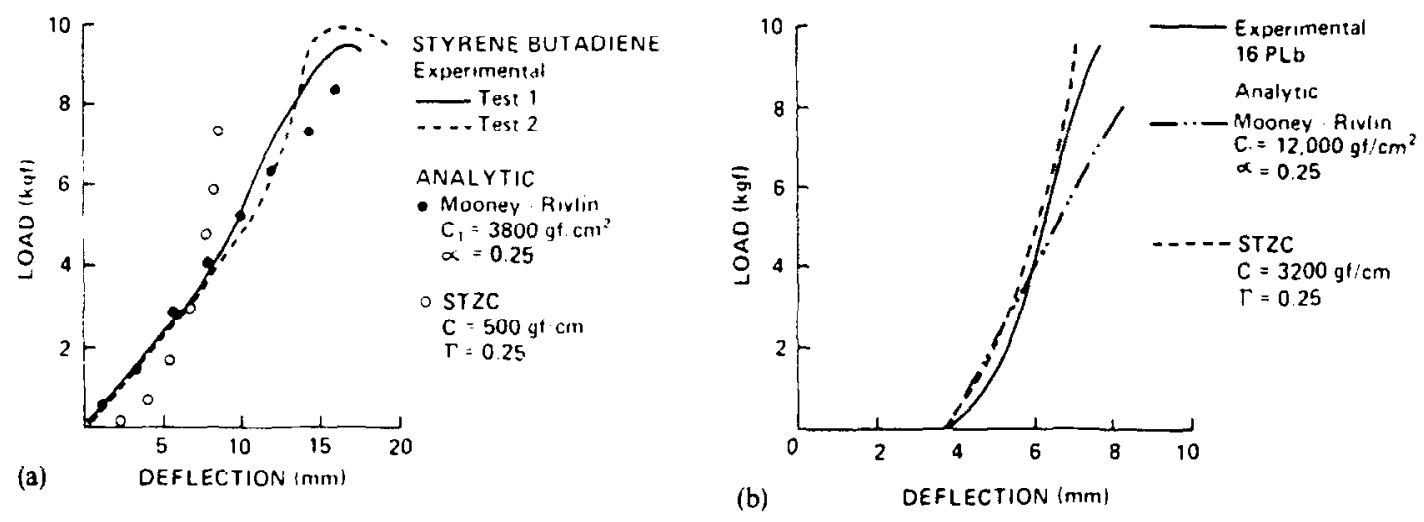

Fig. 4. (a) The MR model adequately characterized the behavior of styrene-butadiene rubber; whereas, (b) the STZC model was superior to the MR model for characterizing the behavior of fetal dura mater.

and the stiffness of the dura mater. Such a correlation was found with the stiffnesses derived from the membrane inflation test performed previously (Kriewall et al., 1983). A larger sample size is required before strong conclusions may be drawn. From parametric and nonparametric analyses of matched pairs from the two sets of tests, it was concluded that the mean of the inflation stiffnesses $\left(C=3800 \mathrm{~g}_{\mathrm{i}} \mathrm{cm}^{-1}\right)$ was greater than that of the biaxial tension stiffnesses $(p \leqslant 0.05)$. A difference was expected, since the material parameters depend on the boundary conditions. Thus, the stiffnesses measured in this test are physiologically valid only insofar as the test boundary conditions simulate the in vivo conditions, as designed.

\section{DISCUSSION}

Assuming physiologic strains of about $10 \%$ based on intrapartum radiographic measurements of biparietal diameter changes (Borell and Fernstrom, 1958), the lowest portion of each loading curve is most relevant clinically. However, no direct measurements of the deformation of the soft tissue connections between the cranial bones have been reported. If such measurements are made, tangent moduli may be defined from these data, simplifying subsequent modeling.

The STZC strain energy function requires two constants, $C$ and $\Gamma$, to specify one curve from a family of curves. $\Gamma$ can range from zero to one. The choice of $\Gamma$ is not critical because the STZC stiffnesses for these data change only slightly over a fairly wide range of $\Gamma$ $(\Gamma=0.25 \pm 0.20$ ).

The numerical procedure requires the specification of an initial deflection and thickness. Both were easily measured to within tolerances needed for repeatable analytic results. Because the SBR tests gave such similar results and the numerical methods yielded consistent results with variables easily specified from the experiments, we concluded that the source of the stiffness variance is the material itself.
All curves of Fig. 5 are the final cycles, taken to failure. As the stiffnesses at the lower cycling levels are less than the overall stiffness reported, the given $C$ s are more correctly upper bounds.

Failure occurred within the ring of free dura mater in all but one of the tests. In that exception (No. $16 \mathrm{PLa}$ ), a tear propagated from one of the punched holes. There was never any apparent slippage from the clamps.

\section{CONCLUSION}

Fetal dura mater exhibits nonlinear load-deflection behavior when subjected to biaxial tension under geometric conditions similar to those encountered by the fetal cranium during delivery. This behavior may be approximated over a wide load range by the constitutive relations proposed by Skalak et al. (1973). Further models of the fetal skull may incorporate stiffness values and failure criteria derived from these data. These models may help us to define mechanical factors that cause birth trauma, and subsequently, help us to avert some of the human tragedy that may be the result of those factors.

Clearly, much more remains to be understood about the birth process and its effects on the fetus. The system is very nonlinear and is affected by many biological variables such as fetal age, fetal presentation, maternal pelvic diameters, and, indeed, any maternal or fetal health factor tending to induce dystocia. This study was not intended to present conclusions based on a mechanical model of the birth process. On the contrary, we hope our initial attempts encourage other investigators to apply advanced engineering methods to this very complex system. After all, every one of us has traveled this perilous path. Most of us escaped unscathed. Then again, maybe we didn't. How much better could we be? Although the risk is small, the consequences of birth trauma can be severe and last a lifetime. Obstetrics could truly benefit from the application of engineering techniques to its unique problems. 

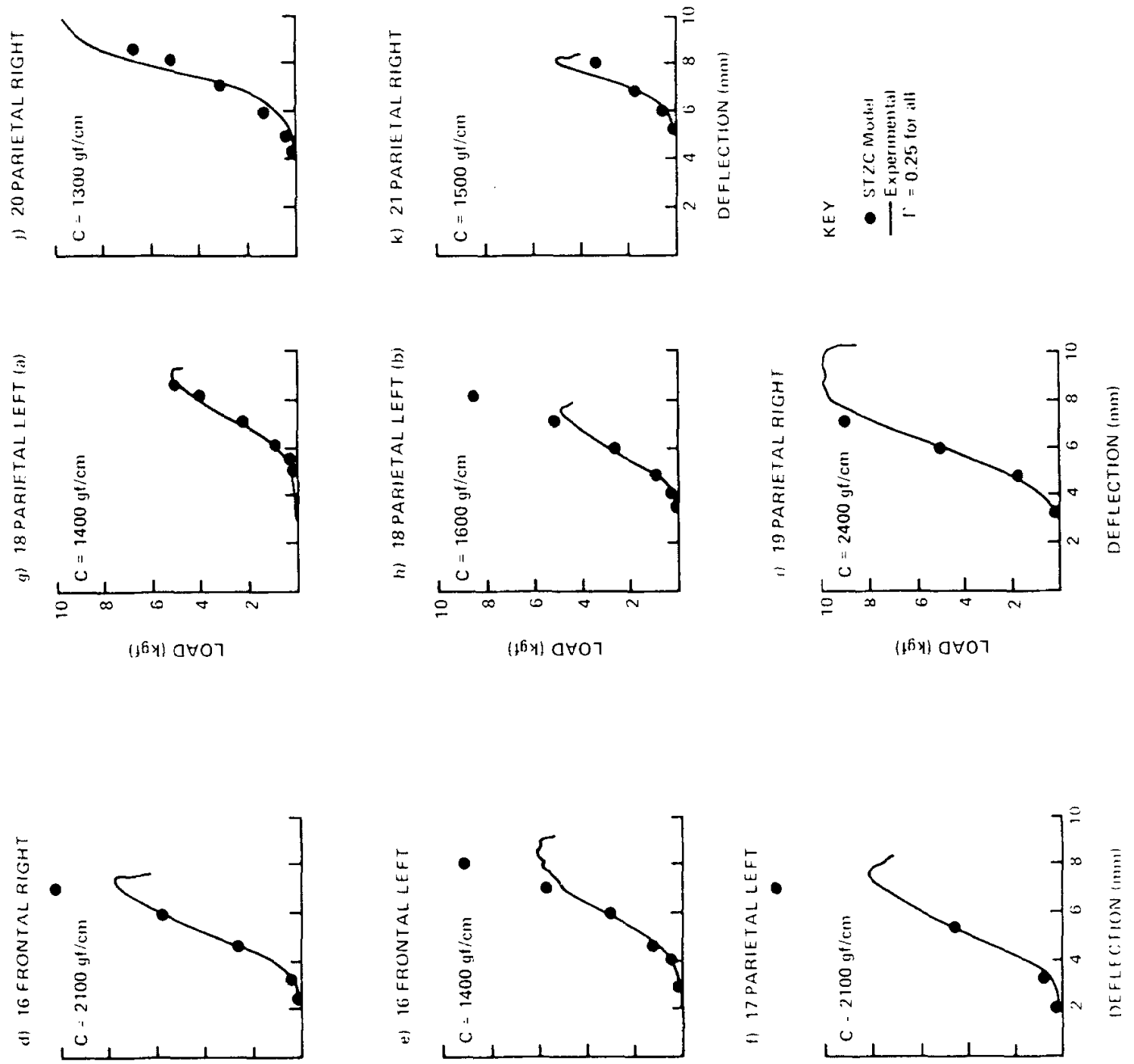

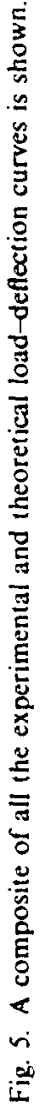
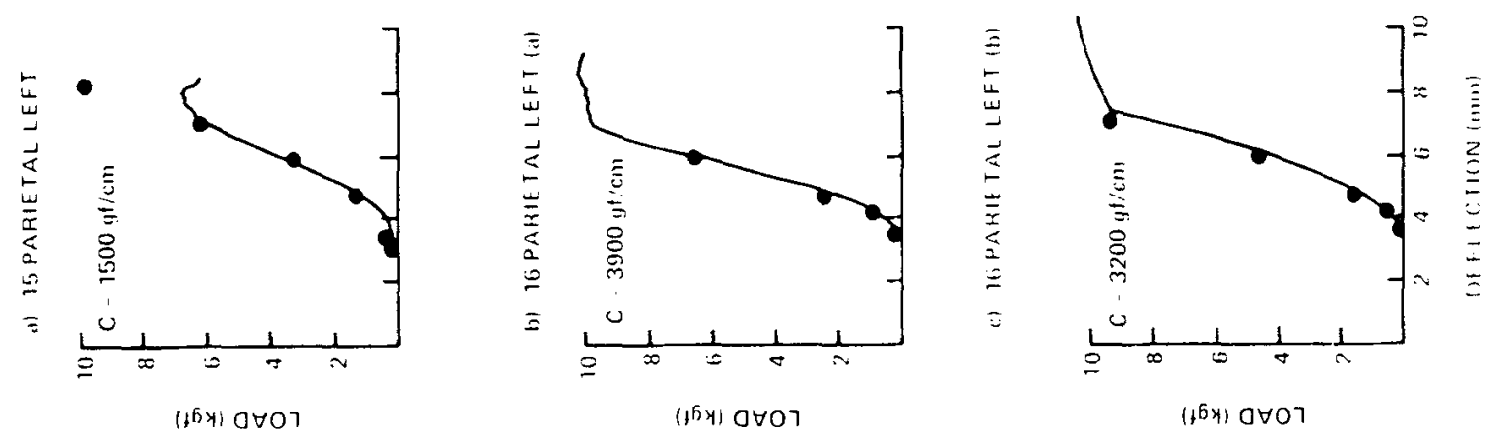
Acknowledgements--This work was supported in part by grant HD 1 i 202 from the Public Health Service.

\section{REFERENCES}

Benedict, R., Wineman, A. and Yang, W. H. (1979) The determination of limiting pressure in simultaneous elongation and inflation of nonlinear elastic tubes. Int. J. Solids Structures 15, 241-249.

Bogen, D. K. and McMahon, T. A. (1979) Do cardiac aneurysms blow out? Biophys. J. 27, 301-316.

Borell, U. and Fernstrom, I. (1958) Die Umformung des kindlichen Kopfes wahrend mormaler Entbindung in regelrechter Hinterhauptslage und bei engem Becken. Gerburtsh Frauenheilk 18, 1156.

Churchill, J. A. (1970) Newborn cerebral trauma. Physical Trauma as an Etiological Agent in Mental Retardation. U.S. Department of Health, Education and Welfare, Washington, DC.

Crisp, J. D. C. (1972) Properties of tendon and skin. Biomechanics - Its Foundations and Objectives (Edited by Fung, Y. C., Perrone, N. and Anliker, M.), pp. 141-179. Prentice Hall, Englewood Cliffs, NJ.

Decraemer, W. F, Maes, M. A. and Vanhuyse, V. J. (1980) An elastic stress-strain relation for soft biological tissues based on a structural model. J. Biomechanics 13,463-468.

Feng, W. W. and Yang, W. H. (1973) On the contact problem of an inflated spherical nonlinear membrane. J. appl. Mech. 40, 202-214.

Fianu, S. (1976) Fetal mortality and morbidity following breech delivery. Acta obstet. gynec. scand. Suppl. 56, 1-85.

Fung, Y. C. (1981) Biomechanics, Mechanical Properties of Living Tissues. Springer, New York.

Glenting, P. (1970) Etiology of Congenital Spastic Cerebral Palsy. F.A.D.L., Copenhagen.

Green, A. E. and Adkins, J. E. (1970) Large Elastic Deformations, 2nd edn. Oxford University Press, London.

Hashimoto, T., Furuya, H., Fujita, M., Yokokawa, T., Kino, H., Kokuho, K, and Tanaka, A. (1980) Biodynamics of the cervical dilatation in human labor. Acta obstet. gynaec. Jap. 32, 1865-1872.

Holland, E. (1922) Cranial stress in the foetus during labour and on the effects of excessive stress on the intracranial contents; with an analysis of eighty-one cases of tentorium cerebelli and subdural cerebral hemorrhage. J. obstet. gynaec. Br. Emp. 29, 549-571.

Kriewall, T. J. (1982) Structural, mechanical, and material properties of fetal cranial bone. Am. J. Obstet. Gynec. 143, $707-714$.

Kriewall, T. J., Akkas, N., Bylski, D. I., Melvin, J. W. and Work, B. A. (1983) Mechanical behavior of fetal dura mater under large axisymmetric inflation. J. biomech. Engng. 105, 71-76.

Kriewall, T. J. and McPherson, G. K. (1981) Effects of uterine contractility on the fetal cranium: perspectives from the past, present and future. Advances in Perinatal Medicine (Edited by Milunsky, A., Friedman, E. A. and Gluck, E.), pp. 295-356. Plenum Press, New York.
Kriewall, T. J., McPherson, G. K. and Tsai, A. C. (1981) Bending properties and ash content of fetal cranial bone. J. Biomechanics 14, 73-79.

Kriewall, T. J., Stys, S. J. and McPherson, G. K. (1977) Neonatal head shape after delivery: an index of molding. J. perinat. Med. 5, 260-267.

Lillien, A. A. (1970) Term intrapartum fetal death. Am. J. Obstet. Gynec. 107, 595-603.

Lindgren, L. (1960) The causes of foetal head moulding in labour. Acta obstet. gynec, scand. 39, 46-62.

McPherson, G. K. and Kriewall, T. J. (1980a) The elastic modulus of fetal cranial bone: a first step towards an understanding of the biomechanics of fetal head molding. J. Biomechanics 13, 9-16.

McPherson, G. K. and Kriewall, T. K. (1980b) Fetal head molding: an investigation utilizing a finite element model of the fetal parietal bone. J. Biomechanics 13, 17-26.

Melvin, J. W., McElhaney, J. H. and Roberts, V. L. (1970) Development of a mechanical model of the human head determination of tissue properties and synthetic substitute materials. Proceedings of the 14th Stapp Car Crash Conference, pp. 221-240. S.A.E., New York.

Pujara, P. and Lardner, T. J. (1978) Deformations of elastic membranes-effect of different constitutive relations. Z. angew. Math. Phys. 29, 315-327.

Quilligan, E. J. and Paul, R. H. (1975) Fetal monitoring: Is it worth it? Obstet. Gynec. 45, 96-100.

Schwarcz, R. L.. Strada-Saenz, G., Althabe, O., FernandezFunes, J., Alvarez, L. O. and Caldeyro-Barcia, R. (1970) Compression received by the head of the human fetus during labor. Physical Trauma as an Etiological Agent in Mental Retardation, pp. 133-143. U.S. Department of Health, Education and Welfare, Washington, DC.

Skalak, R.. Tozeren, A.. Zarda, R. and Chien. S. (1973) Strain energy function of red blood cell membranes. Biophys. J. $13,245-264$

Stewart, K. S. and Philpott, R. H. (1980) Fetal response to cephalopelvic disproportion. Br. J. Obstet. Gynec. 87, 641-649.

Wigglesworth, J. S. and Husemeyer, R. P. (1977) Intercranial birth trauma in vaginal breech delivery: the continued importance of injury to the occipital bone. Br. J. Obstet. Gynaec. 84, 684-691.

Willerman, L. (1970a) Fetal head position during delivery and intelligence. Physical Trauma as an Etiological Agent in Mental Retardation, pp. 105-108. U.S. Department of Health, Education and Welfare, Washington, DC.

Willerman, L. (1970b) Maternal pelvic size and neuropsychological outcome. Physical Trauma as an Etiological Agent in Mental Retardation, pp. 109-112. U.S. Department of Health, Education and Welfare, Washington, DC.

Wineman, A. S. (1976) Large axisymmetric inflation of a nonlinear viscoelastic membrane by lateral pressure. Trans. Soc. Rheol. 20, 203-225.

Wineman, A. S., Wilson, D. and Melvin, J. W. (1979) Material identification of soft tissue using membrane inflation. J. Biomechanics 12, 841-850.

Yang, W. H. and Feng, W. W. (1970) On axisymmetrical deformations of nonlinear membranes. J. appl. Mech. 37, 1002-1011. 